\title{
FEASIBILITY OF IMPLEMENTING IPD APPROACH FOR INFRASTRUCTURE PROJECTS IN DEVELOPING COUNTRIES
}

SUBMITTED: September 2021

REVISED: October 2021

PUBLISHED: November 2021

GUEST EDITORS: Nashwan Dawood, Farzad Pour Rahimian

DOI: $10.36680 /$ j.itcon.2021.048

\author{
Manas Khanna \\ School of Natural and Built Environment, Queen's University Belfast, UK \\ mkhanna01@qub.ac.uk \\ Faris Elghaish, PhD \\ School of Natural and Built Environment, Queen's University Belfast, UK \\ F.elghaish@qub.ac.uk
}

Stephen McIlwaine, PhD

School of Natural and Built Environment, Queen's University Belfast, UK

S.McIlwaine@qub.ac.uk

Tara Brooks, PhD

School of Natural and Built Environment, Queen's University Belfast, UK

T.Brooks@qub.ac.uk

SUMMARY: Alternative project delivery approaches have been proposed to overcome the inefficiencies of conventional delivery methods such as design-bid-build. Integrated Project Delivery (IPD) has recently emerged as a feasible substitute to traditional project delivery approaches. Despite widespread awareness of the benefits of IPD in integration with information and communication technology (ICT) to enhance the delivery of construction projects, IPD implementation has so far been sluggish in developing countries such as India. The feasibility of implementing IPD approach and applying its principles is investigated in this study. It assesses the maturity of delivery techniques, and the potential benefits and limitations of using IPD for infrastructure projects in developing countries, using India as a case study. This study has been carried out using an in-depth investigation of the literature in combination with a qualitative method involving interviews with ten highly experienced BIM professionals from the Indian AEC sector.

The findings of this study have revealed that adopting integrated project delivery while leveraging the BIM process in conjunction with ICT has the potential to effectively deliver mega infrastructure projects in developing countries. The resistance to change, lack of experience and skills, and lack of awareness among project owners are recognized as the primary obstacles to IPD adoption. The main benefits for practice following adoption could include enhanced project delivery, more effective coordination among stakeholders, and greater transparency with cost and time savings through all stages of the project. It is recommended that the regulatory bodies establish governing standards and frameworks, amend regulations to accept IPD concepts, and upskill the workforce through training and knowledge transfer for its successful adoption. One novel aspect of this study may be recognized since most previous research has focused on limitations, benefits, and adoption frameworks for IPD whereas there has been no definitive study on the practicality of IPD combined with BIM and the use of ICT for successful infrastructure project delivery in developing countries. This study contributes to the body of knowledge by serving as an exemplary paper for future studies on the adoption of BIM and ICT approaches such as cloud computing, blockchain, IoT, and mixed realities to deliver projects with integrated project delivery. Furthermore, it provides a deeper understanding of the future of this delivery approach in developing nations.

KEYWORDS: IPD, BIM, ICT, Project Delivery, Infrastructure, Lean Construction

REFERENCE: Manas Khanna, Faris Elghaish, Stephen McIlwaine, Tara Brooks (2021). Feasibility of implementing IPD approach for infrastructure projects in developing countries. Journal of Information Technology in Construction (ITcon), Special issue: 'Construction 4.0: Established and Emerging Digital Technologies within the Construction Industry (ConVR 2020)', Vol. 26, pg. 902-921, DOI: 10.36680/j.itcon.2021.048

COPYRIGHT: (C) 2021 The author(s). This is an open access article distributed under the terms of the Creative Commons Attribution 4.0 International (https://creativecommons.org/licenses/by/4.0/), which permits unrestricted use, distribution, and reproduction in any medium, provided the original work is properly cited. 


\section{INTRODUCTION}

The construction industry is vital to every country's economy. Its contribution is highly contingent on the timely and effective completion of construction projects (Ahmed and El-Sayegh, 2021). Construction projects need a substantial investment of money, time, and resources - these are limited and must be used wisely (Pal and Nassarudin, 2020). The delivery method chosen has a significant impact on project success. For the effective delivery of a project, the activity sequence, material costs, personnel and project management costs are all included in the project delivery process (Jeffrey et al., 2001). Architecture, Engineering, and Construction (AEC) projects yield one-of-a-kind results, necessitating efficient coordination amongst project participants (Salim and Mahjoob, 2020). However, traditional project delivery approaches commonly employed in AEC projects, such as DesignBid-Build (DBB), Design-Build (DB), and Construction Manager at Risk (CMAR), are hampered by goal inconsistency and implementation fragmentation (Salim and Mahjoob, 2020, Azhar et al., 2014). The absence of coordination in these delivery systems is frequently cited by researchers as the cause of their poor results (Andary et al., 2020). To address this issue, it has been suggested that the AEC sector must move towards enhanced stakeholder coordination and more collaborative techniques (Mesa et al., 2016, Azhar et al., 2014, Hale et al., 2009).

In recent years, building requirements have become more complex and the AEC industry has progressed. Therefore, there is a greater demand for optimised solutions and interdisciplinary teams (Adetola et al., 2011, Singhaputtangkul, 2017, Abrishami, Goulding, Pour Rahimian and Ganah, 2015). As a result, lean ideas that emphasise cooperation and process consistency are being used in more projects (Evans et al., 2021, Mossman et al., 2010, Ballard and Howell, 2003). When it comes to goal inconsistency, owners want a better level of quality, lower project costs, and a shorter project delivery time, but builders and designers desire more construction and design fees, respectively. As a result, instead of maximising the project's value, each individual or organisation fights for their own interest. Participants generally work individually and only share their job outputs with a limited number of people, preventing all those working on the project from swiftly absorbing knowledge and experience from other participants. Both of these aspects - goal inconsistency and limited sharing of information and knowledge - contribute to the waste and inefficiency associated with AEC projects (Salim and Mahjoob, 2020, Ma et al., 2018, Abrishami, Goulding and Rahimian, 2020).

Due to the limitations of traditional project delivery methods such as DBB, which include competitive bidding strategies and fixed-price contracts, some project owners have adopted an innovative project delivery approach known as IPD, where BIM in conjunction with ICT technology is essential for its successful deployment (Shendkar and Patil, 2017, Parchami Jalal, Yavari Roushan, Noorzai and Alizadeh, 2020) increasing control over project cost, time, and quality (Becerik-gerber and Kent, 2010). Moreover, the construction environment is changing as sustainable and green buildings become more popular. As the construction industry grows and knowledge of the negative impacts of construction activities on the environment increases, project managers are under enormous pressure to steer their projects toward sustainable growth by adopting more effective environmental management measures (Ahmed and El-Sayegh, 2021). As a result, in order to satisfy the demands of the current construction business, improving project delivery methodologies, selection criteria, and models have become increasingly important. Additionally, the design intent or rationale for such decisions must be produced collaboratively and made available to others throughout the process and subsequently within the project life cycle. Moreover, to limit the effects of complexity \& unpredictability, the design process must be efficiently planned and regulated (Whelton et al., 2001).

According to the India Brand Equity Foundation (IBEF, 2021) and the Economic Survey of India 2020-21 (MOF, 2021), the Indian economy relies heavily on the infrastructure sector. The sector is critical to India's overall growth, and the government places a high priority on enacting laws that will assure the country's production of world-class infrastructure in a timely manner. Adetola et al. (2011) suggest that Infrastructure service distribution is a crucial component of economic growth and GDP contribution.

This is the first study in India to look at the practicality of IPD combined with BIM and ICT for successful infrastructure project delivery, as evidenced by the findings of the literature review. Background information on integrated project delivery and other conventional delivery projects that are employed throughout the construction industry was uncovered by the literature review in this study. Its limitations were evident after a comprehensive literature study and this should be considered a contribution to theory. In addition, the study's main contribution to the body of knowledge is that it investigates the practicality of using BIM and information and communication 
technologies, including cloud computing, blockchain, IoT, and mixed realities, to deliver projects with integrated project delivery. This will serve as a steppingstone for future studies.

With all this in mind, the objectives of this research are to (1) evaluate and assess the current literature on project delivery techniques and integrated project delivery to gain a better understanding of the approach's principles, characteristics, benefits, and shortcomings, (2) examine the existing practices for construction project delivery in India and to evaluate their effectiveness in delivering projects successfully within the project parameters, (3) discover the challenges and contextual setbacks for IPD implementation in India, (4) determine the potential benefits of IPD implementation for infrastructure projects in India, and (5) examine the integration of revolutionary ICTs and BIM for successful delivery with an IPD approach.

The reminder of this paper is structured as follows. Section 2 represents research gap and motivation, followed by section 3 includes conceptual background of the topic. Then, the methodology is presented in section 4 , and followed by the data analysis in section 5 . The discussion is presented in section 6 and finally section 7 includes the conclusion.

\section{RESEARCH GAP AND MOTIVATION}

The benefits of IPD, as well as the role of information and communication technology (ICT) in delivering those benefits, have been thoroughly researched and documented (Ma et al., 2018, McGilly, 2017, Wood, 2017). However, IPD's uptake in the Indian construction sector has been sluggish, and there has been very little study into its viability. Evaluating previous literature confirms that this research is providing a unique contribution to body of knowledge and offers a thorough understanding of existing information on the issue. As evaluated through literature review, Charlesraj and Gupta (2019) studied Beneficiaries and Intermediaries perceptions of IPD implementation in Indian construction, whereas identification of critical challenges for adoption of Integrated Project Delivery were investigated by Othman and Youssef (2021) and Pal and Nassarudin (2020). According to the findings, literature on IPD in India has focused only on the challenges, benefits, principles, and adoption framework. As a result, research on the potential of using IPD with BIM and ICT for enhanced delivery of infrastructure projects in developing countries such as India is yet to be undertaken.

In recent years, IPD research has received much interest. In the construction sector, several academics have proven the necessity of integrating ICT characteristics, such as shared data environment for cloud collaboration. As a result, collaboration is critical for the success of an IPD-based building strategy. Organizations in India and other developing countries are still coordinating and communicating through inefficient, ineffective, and timeconsuming methods. Finding the benefits and drawbacks of this strategy, as well as the reasons for resistance and viable solutions for its effective implementation, is critical for the construction sector's sustainable growth in such countries. The literature recognises the difficulties of adopting IPD in India. For example, Mathews et al. (2017) claimed that combining BIM and blockchain can increase project participants' trust in the AEC sector, while Elghaish et al. (2020b) proposed that blockchain may help with supply chain management. None of the research focuses on the feasibility of IPD implementation while considering the contextual challenges and providing a solution for them. As a result, research on the subject has been restricted to the theoretical conception of the feasibility of the IPD approach in the Indian AEC sector, and this gap is a concern. The usage of IPD for largescale infrastructure projects is becoming crucial as BIM use grows. Integration of BIM and IPD also necessitates a significant amount of study. Furthermore, several components of IPD implementation, notably the lack of qualified and experienced professionals, serve as substantial roadblocks. This study also responds to popular recommendations to combine ICT such as cloud collaboration, Blockchain, IoT, and mixed reality with BIM in a holistic manner. The three main reasons for the incorporation of ICT are: 1) To improve the transparency of work among the project's participants, 2) To enhance coordination and collaboration between stakeholders, 3) To analyse and evaluate stakeholders' performance during the project's execution.

\section{CONCEPTUAL BACKGROUND}

\subsection{Traditional Delivery Methods}

According to Ahmed and El-Sayegh (2021), The term "delivery method" refers to the process of assigning responsibilities to the different stakeholders involved in a project in order to provide a framework for the whole design, procurement, and construction process. In addition, Loulakis (2000) defines a project delivery method as 
"a process by which the components of design and construction including the roles and responsibilities, sequence of activities, cost of materials, and labour are combined to deliver a project." In the construction sector, there is a variety of delivery techniques available, ranging from standard design-bid-build (DBB) to alternative approaches such as design-build (DB) and construction manager at risk (CMR) (Hale et al., 2009). Nevertheless, project delivery techniques have developed throughout time, and the construction industry has offered several modifications and alternatives to satisfy varied client demands.

The DBB method, as the name indicates, requires that the design process be almost complete before soliciting bids for the contractor. Since contractors are not involved in the design process, this method has been criticised for its apparent drawbacks, such as increased project duration and delayed integration (Alleman et al., 2020, Ahmad et al., 2019). The two most common approaches for tackling fragmentation by integrating some of the key stakeholders (clients, designers, and contractors) early in the project are construction management at-risk (CM atrisk) and design-build (DB) (Okere, 2018, Shrestha et al., 2012, Hale et al., 2009). These alternative project delivery approaches, according to studies, have certain advantages over the DBB method. However, the fundamental contractual agreements of these alternative approaches are still attempting to shift risk from one party to another without improving the project environment (Alleman et al., 2020).

\subsection{Integrated Project Delivery}

As defined by the American Institute of Architects AIA (2007), "Integrated Project Delivery (IPD) is a project delivery approach that integrates people, systems, business structures and practices into a process that collaboratively harnesses the talents and insights of all participants to optimise project results, increase value to the owner, reduce waste, and maximise efficiency through all phases of design, fabrication, and construction". Ma et al. (2018) define IPD as all participants' early involvement, close collaboration, and the aggregate of each participant's unique contributions to the development and decision-making process, all with the objective of optimising the project as a whole rather than pursuing the self-interest of their separate entities. Integrated projects are characterised by the owner's, prime designer's, and prime constructor's extremely effective teamwork, commencing at an early design stage and continuing throughout till project handover (AIA, 2007). A study by Mesa et al. (2016) and Kim (2016) supports that, by combining stakeholders' interests and objectives, Integrated Project Delivery (IPD) has developed as a new strategy for providing value to customers and enhancing overall project performance.

IPD with BIM and ICT enhances the deployment of technology while also changing the whole design and construction process. IPD is a novel delivery strategy that is still in its early stages of development and acceptance in developing countries; thus, it presents both opportunities and constraints (Bolpagni, 2013, Zainul Abidin and Amir Shariffuddin, 2019). AIA (2007) highlights the difference in approach between traditional delivery and integrated project delivery approach throughout the various stages of a project. Fewer change orders, greater cost savings, shorter timelines, and fewer requests for information (RFIs) are among the most widely seen benefits of IPD projects, according to the results of a study by Ma et al. (2018). Early contractor engagement has been a hallmark of advanced practice for some time, but the addition of co-location is expected to maximise the benefits of that involvement (Gomez et al., 2018, Babatunde, Ekundayo, Udeaja and Abubakar, 2020). Figure 1 depicts the rationale for using the IPD approach and the advantages it offers if it is effectively applied to a project.

According to Porwal and Hewage (2013), the application of IPD has various limitations and challenges such as lack of leadership, assigning responsibility, and resistance to change. Two key roadblocks to widespread adoption of IPD in developing countries are the lack of standard BIM contract agreements and problems with using BIM as a collaborative framework (Ahmed and Sobuz, 2019, Sheikhkhoshkar et al., 2019). Developing a value-based procurement strategy is difficult, especially for public sector customers who are confined to evaluating competitive bids exclusively on the basis of the low-bid award procedure. Porwal and Hewage (2013) observe that The IPD model requires public organisations and agencies to reform their procurement procedures, and that even though new contracts enabling IPD do exist, they have not been properly investigated and are not yet completely validated or appreciated in the public procurement context. 


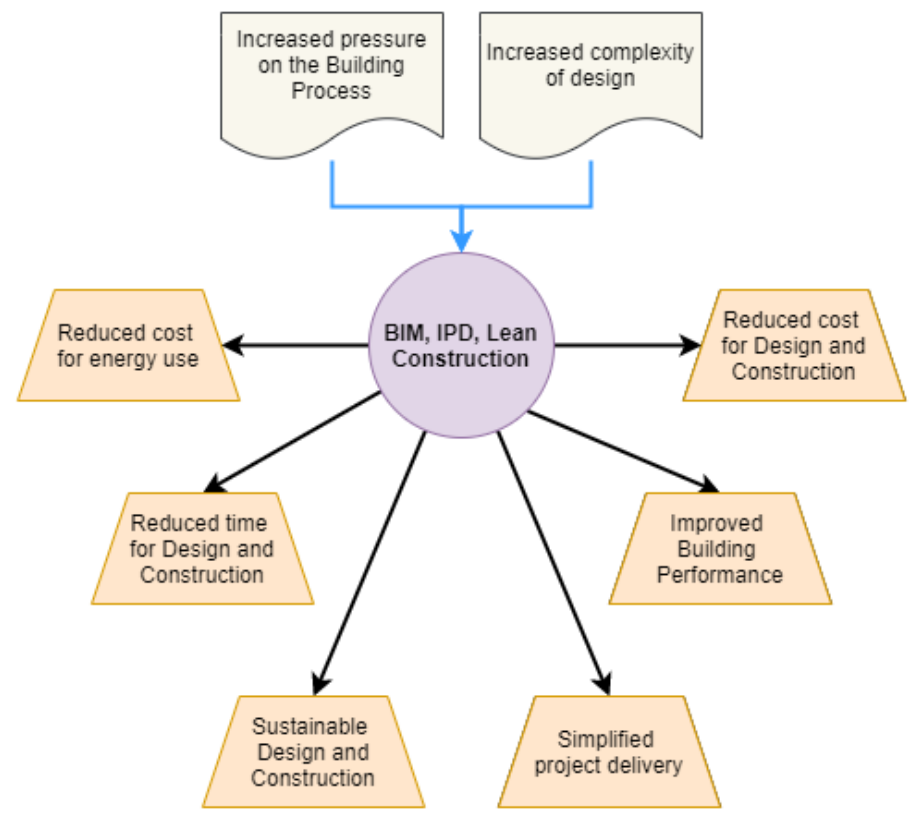

Figure 1: Advantages of IPD, BIM and Lean Construction

\subsubsection{IPD in Indian Construction Industry}

To meet India's economic and development goals, robust, sophisticated infrastructure is required (Excelize, 2020). As a result, some of the country's most important infrastructure initiatives are going beyond simply constructing facilities. They aim to develop characteristics that will help them become more efficient, transparent, and future proof. Charlesraj and Gupta (2019) and Roy et al. (2018) categorised the IPD implementation obstacles in India into four groups: "technological, legal, financial, and cultural". They identified key IPD implementation difficulties from earlier research published across the world, and used expert input and a questionnaire to identify the most pertinent obstacles to the Indian construction sector. As per the findings of their study, the most urgent concerns in each area are listed below. Two of these issues were technical: a lack of clarity in the usage of BIM and the early definition of goals in the absence of a fully completed design. In terms of legal concerns, a new legislative framework was required to allow for value-based contractor selection rather than the traditional criteria of the lowest bidder. It was observed that creating a risk-reward sharing formula and accounting system was a big financial risk. The most challenging cultural barrier was establishing mutual trust and respect due to a lack of previous knowledge of IPD and experience of working together. Concerns regarding cultural transformation must be addressed before IPD can be adopted technically and behaviorally. Owners' lack of knowledge, early stakeholder involvement, and ambiguity in evaluating quality for incentive sharing were other difficulties.

\subsection{BIM and IPD}

The combination of BIM and IPD empowers a level of collaboration that not only improves productivity and minimises inaccuracies, but also allows for the exploration of new innovative concepts. IPD has emerged as a delivery approach that may most effectively facilitate the use of BIM for construction projects (Porwal and Hewage, 2013). The IPD approach compliments BIM tools, and vice versa. It assists in overcoming hurdles to BIM adoption by improving early participation of key contributors, coordination, and increasing the level of trust among prominent stakeholders (Piroozfar et al., 2019). Building Information Modelling, when used in conjunction with an IPD approach, enhances the productivity of the whole construction process from pre-construction to completion. It improves the project's collaboration and coordination across the many teams working on it. It also boosts the efficiency of the departments inside these groups and cuts down on the time it takes to complete their responsibilities. This has been validated through a research conducted by Andary et al. (2020), where the authors concluded that the use of open communication has a substantial impact on decreasing project cost overruns, and team co-location decreases the time required to react to RFIs. The cost of field rework was considerably lowered owing to collaborative decision-making. The adoption of this technology is being facilitated by technological improvements in devices and cloud-based applications. As a result, BIM adoption might be a cost-effective solution for the modern building industry. (Radhakrishnan, 2020). 
Research performed by Shendkar and Patil (2017) acknowledges that BIM is a significant tool for improving project results via effective coordination of project participants and their roles and responsibilities, which are established using the IPD method. BIM has already transformed how firms and their supplier chains deliver projects. Emerging software and virtual reality have become popular, prompting companies to continue investing in these areas in order to stay competitive (Kamunda et al., 2021). The benefits of combining BIM and IPD appeared in several literatures (Elghaish and Abrishami, 2020a, Ma et al., 2018, McGilly, 2017, Wood, 2017). Research conducted by Dossick et al. (2013) and Ballard and Howell (2003) discovered that coupling BIM, IPD, and lean principles enabled integrated collaboration, which improved design outputs and construction products. Chang et al. (2017) affirmed the ability of BIM to enhance the appreciation of IPD by evaluating the results of adopting BIM in 145 projects.

According to (Shendkar and Patil, 2017), the scheduling and sequencing of the model to coordinate virtual building in time and location is part of the construction planning process. A virtual construction can be connected with a schedule of expected construction progress. Time becomes the fourth dimension when scheduling is used (4D) (Sheikhkhoshkar et al., 2019), whereas cost is introduced as the fifth dimension because of the use of quantities (5D). Quantity take-off and price are the two primary components of a cost estimate.

The research conducted by Elghaish et al. (2019b) indicated that integrating IPD with BIM is the best approach to deliver construction projects because of its capacity to maximise value via a risk/reward sharing mechanism. Meanwhile, BIM tools may supply all necessary technologies throughout the project delivery process (Goulding and Rahimian, 2012). The paper by Elghaish et al. (2019a) presents a cash flow methodology framework for maximising the benefits of employing 4D and 5D BIM in the IPD technique for producing project cash flow. According to Wang et al. (2020), the effectiveness of Building Information Modelling (BIM) enabled project delivery requires a greater knowledge of collaboration among different stakeholders. Nonetheless, Kurwi (2017) has highlighted a lack of efficient standards for the collaboration of diverse disciplines at all phases of a project.

\subsection{Integration of ICT and IPD}

McGilly (2017), in an industry report for Autodesk University, discusses the integration of IPD with Cloud platforms. According to him, Client demands require that businesses will be working to tighter timelines and fees; thus, projects are shifting more towards a common data environment. As a result, not just the workflow but also how data is handled must become more efficient, which could be supported by working on a cloud platform. Moreover, evaluating effective workflows, depending on your network bandwidth and model size, uploading, and downloading files from typical file exchange services might take several hours (Azhar et al., 2014). When making changes or addressing coordination difficulties, teams strive to act quickly. To aid this, these changes must be seen immediately, which cloud-based hosting models and data may provide. Realizing that completion of the project is a data-intensive operation, there has been a huge increase in concepts and technology linked to the sharing and management of infrastructure project data during the past several years. Recent research conducted by Alashhab et al. (2021) on the "Impacts of Coronavirus Pandemic on Technology and Cloud Computing Systems," revealed that the work-from-home culture is heavily reliant on cloud computing (CC) technologies which allow employees to do tasks more quickly. During the Covid-19 outbreak, the author concedes, "the role of the cloud computing environment (CCE) has emerged as an unsung hero." The next wave of digital transformation is expected to necessitate appropriate solutions since conventional technologies will be unable to handle Big Data and organisational requirements.

Elghaish et al. (2020b) propose a strategy for implementing blockchain technology into IPD applications. By coding the three major activities of IPD projects: reimbursement expenditures, profit, and cost savings as functions of the IPD smart contract, the framework would enable core project team members to perform all financial transactions automatically (Elghaish and Abrishami, 2020c). The proposed usage of the IPD-based blockchain provides a variety of benefits, including 1) simplifying decision-making among IPD core team members, 2) recording cumulative risk/reward values for each network participant, and 3) establishing smart contracts that address legal problems (Hunhevicz et al., 2020, Elghaish et al., 2020b)

The Internet of Things (IoT) envisions a future in which digital and physical things or objects (such as mobile devices, machines, and tools) may be linked together using appropriate information and communication technologies to allow a variety of applications and services (Razzaque et al., 2015, Rahimian et al., 2008). Teizer et al. (2017) present the notion of perpetual availability of up-to-date real performance data sets using Internet-of- 
Things (IoT) technology that incorporates environmental and localization data in a cloud-based BIM platform in a study. It also emphasises the potential for linked, digital, and smart technology to be used in construction engineering and management, as well as facility management and operations (Tagliabue and Ciribini, 2018, Kim et al., 2018, Chung et al., 2020, Teizer et al., 2017).

\section{RESEARCH METHODOLOGY}

A combination of approaches were used to conduct the study investigation, as indicated in Error! Reference source not found.. To begin, a thorough literature review was carried out in order to acquire background information and determine what was previously known about project delivery techniques and IPD. Books, papers from academic and professional international journals, government and industry reports, and conference proceedings were included in the search for literature. Conducting a literature review contributes to a better understanding of the nature of the research and, as a result, the formulation of appropriate aims and objectives (Abowitz and Toole, 2010). Furthermore, the literature study assisted in attaining the goals of evaluating existing construction project delivery techniques and identifying obstacles and contextual barriers for IPD adoption in developing countries. The information gathered from the literature is employed then used to create interview questions in order to perform a mono-method qualitative analysis. The characteristics of IPD and its implementation challenges were discovered through literature research, which were then verified by the qualitative analysis of in-depth interviews.

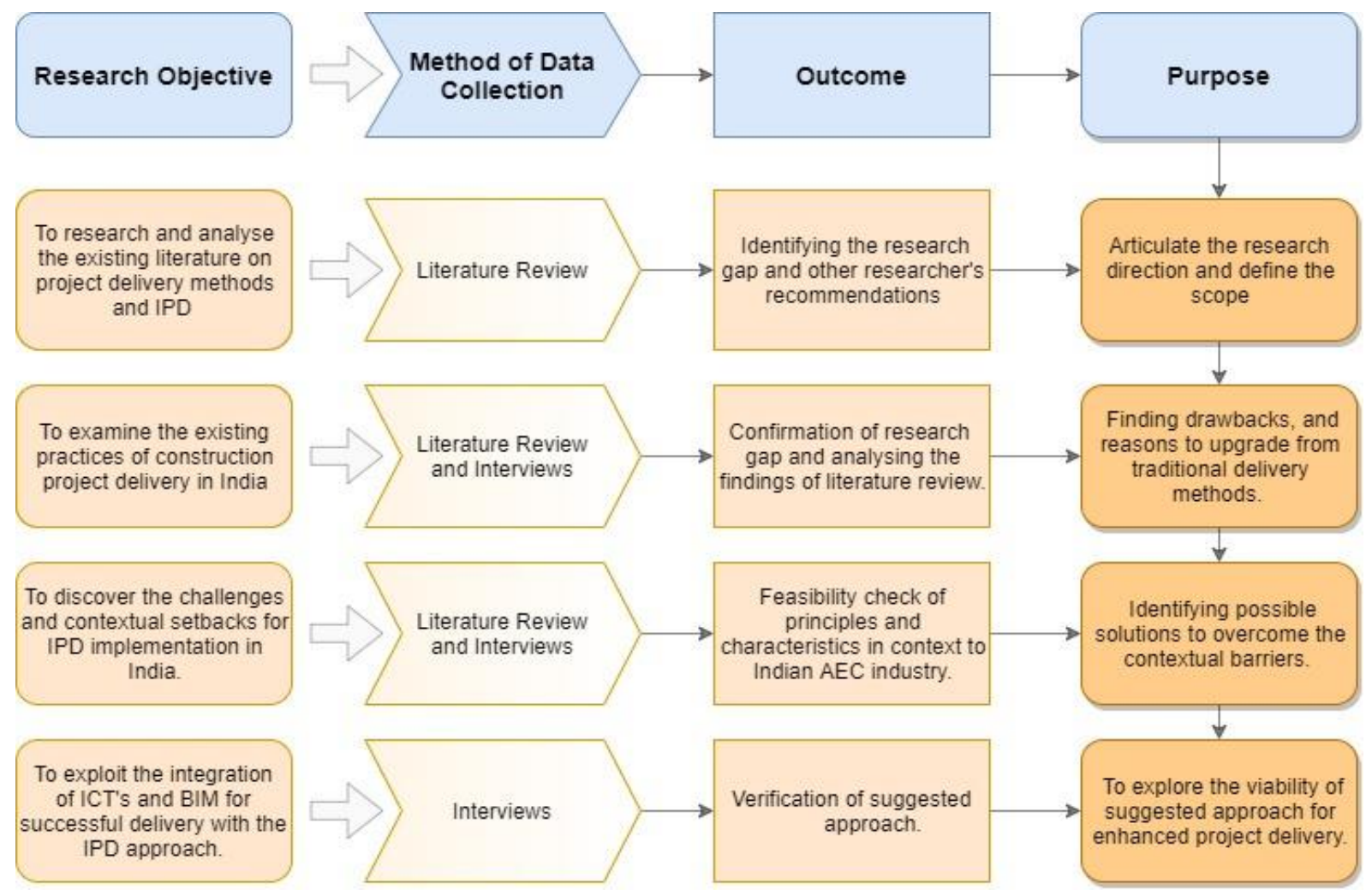

Figure 2: Research design and flow

The purpose of this assessment was to analyse the study findings by interviewing industry professionals and academic staff about the feasibility of implementing the IPD approach for infrastructure projects in developing nations. Based on the findings of the literature review, semi-structured interview's questions with industry practitioners were designed and undertaken using an inductive research technique. The interview participants were discovered using LinkedIn search phrases such as IPD, BIM, SaaS, Infrastructure, and Virtual construction. The participants were identified based on the following criteria: (1) having worked in the Indian construction industry, (2) being familiar with the theoretical and practical understanding of BIM, and (3) being knowledgeable of the information and communication technologies used in the construction sector. Participants' knowledge and 
understanding of IPD was assessed on a scale of one to five, with one being the least familiar and five being the most knowledgeable. Error! Reference source not found. below shows the profiles of the Interview participants.

A semi-structured interview was preferred over a structured interview because it allows for more flexibility in approaching various respondents while yet addressing the same areas of data gathering. The interview questions were created using concepts and information gathered from the literature research. Based on the respondent's profile and introduction, the first section of the interview questions included a combination of closed and openended questions. In the second section, questions on the characteristics of IPD and its integration with BIM and ICTs were addressed, followed by open-ended general questions with follow-up questions concerning the future of delivery methods in India. Following that, the challenges, and contextual barriers for implementing IPD in the Indian construction sector, as well as the reasons and solutions for the industry's unwillingness to embrace this approach, were explored. The gathered data was then analysed to look for patterns for the exploratory research. The interviews were conducted online using Zoom meetings and were recorded with the participant's consent to ensure an accurate assessment of the conversations and to avoid losing data. Transcriptions of the recorded interviews were created using the transcribe tools of Microsoft Word (online version) once the interviews were completed, always ensuring security of the data. Later the transcripts were further modified to improve the efficacy of the findings. These transcripts were then transferred to NVivo software where the analysis was performed.

Table 1: Profiles of the Interviewees

\begin{tabular}{|c|l|l|l|l|l|}
\hline $\begin{array}{l}\text { Participant } \\
\text { IDs }\end{array}$ & Job Role & $\begin{array}{l}\text { Industry } \\
\text { Experience }\end{array}$ & $\begin{array}{l}\text { Understanding of } \\
\text { IPD (1-5) }\end{array}$ & $\begin{array}{l}\text { Familiar } \\
\text { with BIM } \\
\text { Yes/No) }\end{array}$ & $\begin{array}{l}\text { Educational } \\
\text { Qualification }\end{array}$ \\
\hline $\mathbf{A}$ & Founder and CEO & 27 years & 5 & Yes & B.Arch. \\
\hline $\mathbf{B}$ & $\begin{array}{l}\text { Associate Director } \\
\text { (BIM) }\end{array}$ & 22 years & 3 & Yes & B.Arch. \\
\hline $\mathbf{C}$ & $\begin{array}{l}\text { Co-Founder and } \\
\text { CEO }\end{array}$ & 13 Years & 4 & Yes & $\begin{array}{l}\text { MSc Construction } \\
\text { Project Management }\end{array}$ \\
\hline $\mathbf{D}$ & BIM Manager & 11 Years & 4 & Yes & B.Arch. \\
\hline $\mathbf{E}$ & $\begin{array}{l}\text { Sales Head - AEC } \\
\text { India }\end{array}$ & 31 Years & 5 & Yes & B.Arch. \\
\hline $\mathbf{F}$ & $\begin{array}{l}\text { CEO, Keynote } \\
\text { speaker }\end{array}$ & 21 Years & 5 & Yes & $\begin{array}{l}\text { MCA (Computer } \\
\text { applications), MSc } \\
\text { Computer science }\end{array}$ \\
\hline $\mathbf{G}$ & $\begin{array}{l}\text { Co-Founder/ } \\
\text { Architect }\end{array}$ & 15 Years & 5 & Yes & $\begin{array}{l}\text { MSc Strategic } \\
\text { management }\end{array}$ \\
\hline $\mathbf{H}$ & Founder and CEO & 9 Years & 3 & Yes & $\begin{array}{l}\text { MSc Construction } \\
\text { Project Management }\end{array}$ \\
\hline $\mathbf{J}$ & $\begin{array}{l}\text { BIM manager, } \\
\text { Keynote speaker }\end{array}$ & 14 Years & 5 & $\begin{array}{l}\text { MSc City/Urban, } \\
\text { Community and } \\
\text { Regional Planning }\end{array}$ \\
\hline K & Strategy consultant & 10 Years & 5 & $\begin{array}{l}\text { BE Civil, MSc } \\
\text { Construction Project } \\
\text { Management }\end{array}$ \\
\hline
\end{tabular}

\section{DATA ANALYSIS}

Initially, a mind map for the entire hypothesis was constructed with IPD in mind, which aided in developing significant themes for the analysis. The information in the mind map highlighted some essential subjects, which assisted in gaining initial comprehension of the data. An inductive thematic analysis was then performed to evaluate data from the interviews, and the results were correlated to highlight relevant themes for discussion.

In this paper, actual statements are presented in quotes to depict the lived experience of the practicing professionals. Document reviews were then used to confirm evidence gathered during interviews and to validate information provided by respondents by comparing transcriptions to information included in the examined documents. The evaluation of documents improved the research's credibility and internal validity (Taylor et al., 2015). Interview quotes have been enhanced for readability, and it is stated where the data gathered from interviews is used, as well 
as what document review is used. The challenges, benefits, and solutions of IPD implementation in India were identified after combining the data from the literature and interviews which further helped in achieving the research objectives.

\subsection{Thematic Data Analysis}

Thematic analysis has been used to produce seven primary themes from the research. As indicated in figure 2 and 3, these themes were subdivided into distinct codes and child codes. The number of files in which the code has been used, as well as the number of times a code has been referenced, are also highlighted in the figure.

Some references are allocated to multiple codes since they are relevant to a variety of subjects.

Figure 3 below represents the identified themes that result from the data analysis and Figure 4 highlights the themes subcategorised into codes and sub-codes.

As indicated in the figure, "IPD in India" has been mentioned the most, with 299 references, and all the participants have discussed it. With 128 references, Code "contextual setbacks" have been addressed the maximum number of times, while the "current status of delivery methods" has been referenced 91 times. The most identified setbacks are (1) Insufficient skills and experience, (2) Mindset, (3) Lack of interest to upgrade, (4) Lack of awareness, (5) and Slow adoption. From Figure 4, it is clear that "IPD and BIM" is a dominant theme, and every participant emphasised the need of combining BIM and ICTs for the effective implementation of IPD. The highest number of references for "benefits of IPD" is coded to enhanced project delivery (21 references), simplified project delivery and time savings (16 references), and last but not least, cost savings (15 references). With 12 and 10 references, respectively, the next closest recognised benefits are reduced errors and risks and fewer change orders. "Challenges for implementation of IPD" occurred fewer times, with a total of 33 references. The most common were lack of skilled staff (10 references), breaking of mindset and cost implications (6 references). In addition, the challenge of "bringing stakeholders together" was mentioned only by participants E, H, J, and K.

As per the number of references coded, "Early involvement of key project parties" is the most coded characteristic of IPD, with 23 out of a total of 115 . The second most coded references (18) are "collaboration" and "no tendering," which are followed by "trust and respect between stakeholders," which has 15 coded references. Then there are 13 and 12 references for "Jointly developed project goals" and "Shared risk and rewards," respectively. Lastly, there are other themes such as "Decision making and control" and "multi-party contracts," each having only eight coded references and was only mentioned by $5 / 6$ out of 10 participants.

The participants also discussed the current status of delivery methods in India, with 9 of the 10 participants emphasizing the role of technology and "technology adoption" in the Indian construction sector. Participants A, C, D, F, G and J believed that technology adoption, even in the case of BIM adoption, has been very slow in India. However, things have started improving and now BIM is gaining popularity and is also being included in the contracts. Participants A, B, D, and J reported that the technology is already available in the market, but to fully adopt and use it, the industry needs the right people and processes with the necessary skills and competencies. As quoted by participant $\mathrm{J}$,

"The biggest challenge for IPD is to have the Expertise, Experience, and Excellence. First, you need to have the right people in place who have that expertise. Secondly, they need to have that experience as well, and lastly, all being driven to excel in their very best. These are the three E's of IPD, and they are not very easy to accomplish."

Furthermore, participants A, H, and K highlighted the shift from design-bid-bid or design-build to EPC contracts. Furthermore, participants A, C, G, H, and K indicated the "Partial adoption" of IPD for large scale projects in India. When asked if having "No tender" as an IPD characteristic for construction projects in India would be feasible, 6 out of 10 participants saw it as a difficulty since most clients prefer to have a bidding process and because contracts are sometimes awarded based on the lowest bidder who can demonstrate adequate technical capabilities. Participants A, D, and F discussed having a "Negotiated contract" instead of "No tender", where a selected party based on its technical capabilities will be negotiated by the client through a multi-party contract. 


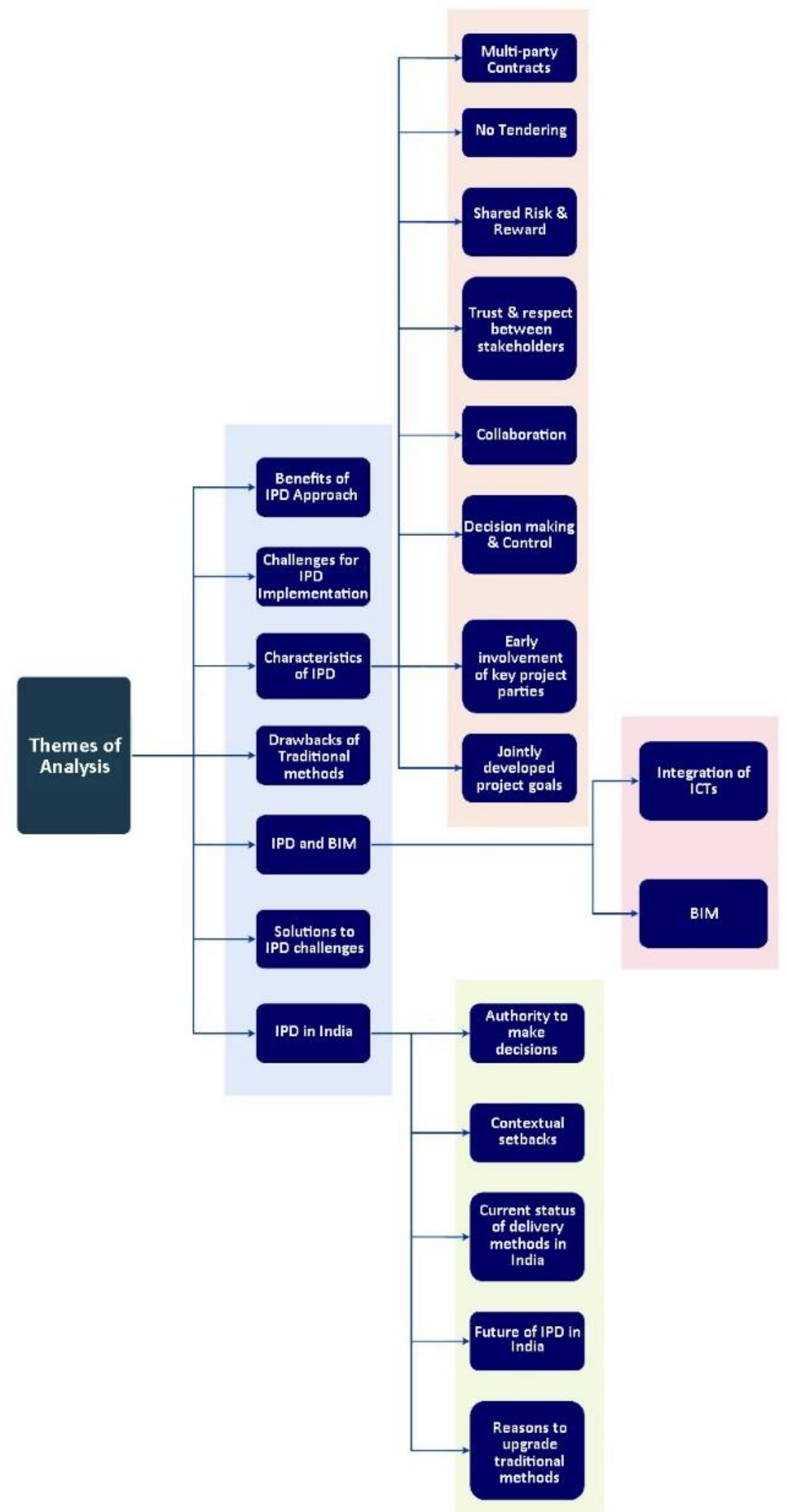

Figure 3: Research Themes 


\begin{tabular}{|c|c|c|}
\hline \multicolumn{3}{|l|}{ Codes } \\
\hline (†) Name & -Files & References \\
\hline BO Benefits of IPD approach & 10 & 120 \\
\hline O cost saving & 10 & 15 \\
\hline O Easy Operation and Maintenance & 3 & 4 \\
\hline O Enhanced project delivery & 9 & 21 \\
\hline O Improved Coordination among stakeholders & 4 & 9 \\
\hline Incentives on successful project delivery & 2 & 3 \\
\hline O Less change orders & 7 & 10 \\
\hline O Reduced errors and risk & 8 & 12 \\
\hline O Simplified project delivery & 7 & 16 \\
\hline O Sustainable buildings & 4 & 6 \\
\hline O Time saving & 10 & 16 \\
\hline O Transparency of work & 2 & 2 \\
\hline Waste reduction & 5 & 6 \\
\hline E $\mathrm{O}$ Challenges for implementation of IPD & 5 & 33 \\
\hline O Breaking of mindset & 4 & 6 \\
\hline Resistance to change & 1 & 1 \\
\hline O Bringing stakeholders together & 4 & 4 \\
\hline O cost implications & 5 & 6 \\
\hline Difference between theory and practice & 1 & 2 \\
\hline O Lack of skilled staff & 5 & 10 \\
\hline EO Characteristics of IPD & 10 & 115 \\
\hline O collaboration & 8 & 18 \\
\hline O Decision making and control & 6 & 8 \\
\hline E Early involvement of key project parties & 10 & 23 \\
\hline O Jintly developed project goals & 6 & 13 \\
\hline Multi-party contracts & 5 & 8 \\
\hline O No Tendering & 10 & 18 \\
\hline O Shared Risk and Reward & 7 & 12 \\
\hline O Trust and respect between stakeholders & 7 & 15 \\
\hline O Drawbacks of traditional methods & 9 & 16 \\
\hline O Further research & 4 & 6 \\
\hline O Evolution of contracts & 2 & 3 \\
\hline O Remotely accessible cloud management & 1 & 1 \\
\hline O Technology for surveying & 1 & 2 \\
\hline$=\mathrm{O} \mid \mathrm{PD}$ and $\mathrm{BIM}$ & 10 & 87 \\
\hline O BIM & 9 & 27 \\
\hline O Integration of ICTs & 10 & 43 \\
\hline
\end{tabular}

\begin{tabular}{|c|c|c|}
\hline$A O_{1 P D}$ in India & 10 & 299 \\
\hline O Authority to make decisions & 4 & 6 \\
\hline$=\mathrm{O}$ Contextual setbacks & 9 & 128 \\
\hline O Changing market scenario & 6 & 8 \\
\hline Cultural setbacks & 4 & 4 \\
\hline Different rules and regulations & 4 & 9 \\
\hline O Fragmented approach & 3 & 7 \\
\hline O High investment cost of implementation & 5 & 6 \\
\hline O Insufficient skills and experience & 7 & 15 \\
\hline O lack of awareness & 6 & 13 \\
\hline O Lack of confidence between parties & 4 & 4 \\
\hline O Lack of interest to upgrade & 9 & 14 \\
\hline O lack of transparency & 3 & 6 \\
\hline O Mindset & 7 & 15 \\
\hline O Non avaliability of suitable IPD contracts & 3 & 8 \\
\hline Personal Interest & 5 & 5 \\
\hline Slow adoption & 6 & 13 \\
\hline O Underpaid employees & 1 & 1 \\
\hline =O Current status of delivery methods in India & 10 & 91 \\
\hline Bidding process & 8 & 12 \\
\hline O EPC Contracts & 3 & 9 \\
\hline O Negotiated contract & 3 & 5 \\
\hline O Partial IPD adoptation & 5 & 10 \\
\hline O Technology adoption & 9 & 28 \\
\hline$=O$ Future of IPD in India & 9 & 46 \\
\hline O combination of IPD and traditional methods & 5 & 7 \\
\hline O Reasons to upgrade traditional methods & 9 & 28 \\
\hline$\Xi$ O Solutions to IPD challenges & 9 & 112 \\
\hline C Change of mindset & 6 & 6 \\
\hline Client's initiative & 5 & 7 \\
\hline O Educating the client & 6 & 10 \\
\hline forced adoption & 7 & 8 \\
\hline O Govemment Initiatives & 8 & 15 \\
\hline Incentivizing successful adoption & 3 & 3 \\
\hline O Indisputable IPD contracts & 5 & 9 \\
\hline O Knowledge transfer through institutions & 3 & 5 \\
\hline Setting up case studies & 9 & 17 \\
\hline O Setting up standards and framework for implementation & 6 & 13 \\
\hline O Training staff & 7 & 10 \\
\hline O Iransparency & 3 & 6 \\
\hline
\end{tabular}

Figure 4: Themes, Codes, and Sub-codes - Thematic Analysis

As indicated in Figure 4, the code "Reasons to upgrade traditional method" has been referenced 28 times. Participants A, B, C, D, and G share the opinion that the traditional delivery methods lack collaboration, because of which there are communication and coordination issues when the information is transferred from one party to another. Moreover, participants A, B, E, and G stated that the current delivery methods in India are not productive and lack efficiency. Time delays and Cost overruns have also been mentioned as one of the drawbacks of these traditional approaches by participants B, C, E, and K. When questioned about the "future of IPD in India," the majority of the participants agreed that the future is promising and that present delivery techniques can be improved. Participants A, B, F, H, and J stated that IPD would not replace conventional methods but will run alongside them and that construction projects in India will use a "combination of IPD and traditional methods."

\subsection{Mind Map}

A mind map is also used to form a link between the codes as well as hierarchies to facilitate the thematic analysis of interview transcripts (QSR, 2018b). Figure 5 shows the mind map linking the interview codes, which correlates with the thematic and cluster analysis of the interviewee's answers. The concept begins with IPD's core theme, and all subsequent themes, codes, and sub-codes are interconnected to it in some respect. To integrate the issues, status, and future of traditional delivery methods in India, another floating concept of "Traditional delivery methods" is utilized for comparison, as illustrated in Figure 5. 




Figure 5: Mind map of analysis

(c) (i)

ITcon Vol. 26 (2021), Khanna et al., pg. 913 


\subsection{Matrix Coding Query}

Further analysis can be found in Table 2, which shows the breakdown of solutions to IPD implementation discussed by each participant. This analysis was generated by performing a matrix coding query on NVivo12. According to QSR (QSR, 2018a), Matrix Coding queries allow you to examine where two lists of entities' coding overlap. Matrix Coding inquiries allow you to ask a variety of questions about patterns in your coded data and obtain access to the content that demonstrates those patterns (QSR, 2018a). The number of references for each solution by each participant is indicated with a colour coding. The darker the colour of the cells indicates a higher number of references.

Table 2: Matrix Coding Query

\begin{tabular}{|c|l|l|l|l|l|l|l|l|l|l|}
\hline $\begin{array}{l}\text { Solutions to Implementation/ } \\
\text { Participants }\end{array}$ & $\mathbf{A}$ & $\mathbf{B}$ & $\mathbf{C}$ & $\mathbf{D}$ & $\mathbf{E}$ & $\mathbf{F}$ & $\mathbf{G}$ & $\mathbf{H}$ & $\mathbf{J}$ & $\mathbf{K}$ \\
\hline 1. Change of mindset & 1 & 1 & 1 & 1 & 1 & 0 & 0 & 0 & 1 & 0 \\
\hline 2. Client's initiative & 0 & 0 & 0 & 2 & 1 & 0 & 1 & 0 & 1 & 2 \\
\hline 3. Educating the client & 0 & 0 & 1 & 3 & 1 & 2 & 0 & 2 & 1 & 0 \\
\hline 4. Forced adoption & 1 & 2 & 1 & 0 & 1 & 0 & 1 & 0 & 1 & 1 \\
\hline $\begin{array}{l}\text { 5. Government } \\
\text { Initiatives }\end{array}$ & 1 & 2 & 3 & 1 & 3 & 0 & 1 & 0 & 2 & 2 \\
\hline $\begin{array}{l}\text { Incentivizing } \\
\text { successful adoption }\end{array}$ & 0 & 0 & 1 & 0 & 1 & 0 & 0 & 0 & 0 & 1 \\
\hline $\begin{array}{l}\text { Indisputable IPD } \\
\text { contracts }\end{array}$ & 0 & 0 & 1 & 3 & 1 & 1 & 0 & 0 & 0 & 3 \\
\hline $\begin{array}{l}\text { Knowledge transfer } \\
\text { through institutions }\end{array}$ & 0 & 0 & 0 & 1 & 0 & 2 & 0 & 2 & 0 & 0 \\
\hline $\begin{array}{l}\text { Setting up case } \\
\text { studies }\end{array}$ & 5 & 1 & 0 & 1 & 2 & 1 & 1 & 4 & 1 & 1 \\
\hline $\begin{array}{l}\text { 10. Setting up standards } \\
\text { and framework }\end{array}$ & 0 & 0 & 1 & 3 & 2 & 0 & 0 & 2 & 2 & 3 \\
\hline 11. Training staff & 0 & 3 & 0 & 1 & 2 & 0 & 1 & 1 & 1 & 1 \\
\hline 12. Transparency & 1 & 0 & 0 & 0 & 0 & 2 & 0 & 3 & 0 & 0 \\
\hline
\end{tabular}

All the participants, except for participant C, mentions the solution "Setting up case studies." Participants A and $\mathrm{H}$ have discussed the solution more than the rest, as indicated in Table 2 by the deeper hue of the cell. Most of the participants also highlighted the solutions such as government initiatives, staff training, and the formation of frameworks and standards for the successful implementation of IPD in India. Incentivizing successful adoption is the least mentioned solution, with only three participants mentioning it.

\section{DISCUSSION ON FINDINGS}

The findings from the study show that the current state of Integrated Project Delivery in India is in its early stages, literature (Pal and Nassarudin, 2020, Charlesraj and Gupta, 2019, Roy et al., 2018, Sarkar, 2015) and the qualitative research conducted in this study indicate that the tendency will continue to grow. Participants A, E, F, G, J, K who had used or worked partially with IPD were very positive about its future scope, while those who had not had the opportunity to do so were ready to adopt this innovative method once some of its apparent flaws have been resolved. The significance of technology and "technology adoption" in the Indian construction industry is emphasised by 9 of the ten interviews. Participants A, C, D, F, G, and J believed that technology adoption in India has been sluggish, even in the case of BIM adoption. These findings agree with those obtained by literature (Pal and Nassarudin, 2020). The reason for this is unclear, although it might be related to the industry's fragmented approach and apprehension to accept emerging innovations. However, there is a belief that things have begun to improve, and BIM is now becoming more popular, as well as being incorporated in contracts (Participants A, C, F, G J). Participants A, H, and K emphasised the switch from design-bid-bid or design-build to EPC contracts that focus more on collaboration and integration, supporting the relationship between IPD approach and EPC contracts (Ahmed and El-Sayegh, 2021, Adetola et al., 2011). Participants A, C, G, H, and K also acknowledged India's "partial acceptance" of IPD for large-scale infrastructure projects. These findings might be attributed to increased 
project complexity and a desire for world-class sustainable infrastructure (Ahmed and El-Sayegh, 2021, MOF, 2021, Mesa et al., 2016).

During the Interview, when participants were asked if having "No tender" as an IPD characteristic for construction projects in India was possible, 6 out of 10 participants regarded it as a challenge. This challenge has also been identified by Charlesraj and Gupta (2019) in their research. These results further support the idea of having a 'Negotiated contract' proposed by participants A, D, and F, in place of 'No tender', in which the client negotiates a multi-party contract with a selected party based on its technical abilities. However, there are still many unanswered questions about the practicability of having 'No tender' because of the lack of transparency, trust, and confidence within parties.

As stated by Whelton et al. (2001), traditional delivery and contracting techniques envision discrete silos of responsibility that result in inefficiencies anytime a task is handed from one person to another. Besides, conventional delivery approaches suffer because participant's success and the project's success are not always linked (Wang et al., 2020). This has also been supported by thematic analysis of interviews where the need for shared risks and rewards for successful project delivery have been referenced 12 times. As per the research conducted by Ahmed and El-Sayegh (2021), Shendkar and Patil (2017) and according to participants A, B, C, D, and G, traditional project delivery methods lack coordination, resulting in misunderstanding and communication problems when data is transmitted from one party to another.

Furthermore, participants A, B, E, and G acknowledges that India's present project delivery methods are ineffective and inefficient, which match those observed in earlier studies by Ahmed and El-Sayegh (2021). Time delays and budget overruns due to repetitive work, inefficient collaboration among relevant parties, and modifications that occur after construction is completed were discovered to be the primary contributors to the need for the implementation of this approach. Participants B, C, E, and K also highlighted time delays and cost overruns (Whelton et al., 2001) as disadvantages of these conventional methods. Moreover, conflicts between designer and contractor have also been identified as a major drawback.

As highlighted in the literature, IPD aims to improve project outcomes by working together to align key stakeholders' goals through shared risk and reward, early project stakeholder engagement, and a multiparty agreement (Sarkar, 2015, AIA, 2007). In addition, collaborative decision making \& control and trust and respect between project stakeholders have also been identified as the key principles of IPD (Shendkar and Patil, 2017, Mossman et al., 2010). The interviewees also highlighted the importance of these characteristics, which has been coded through NVivo software. As per the number of references coded, 'Early involvement of key project parties' is the most coded characteristic of IPD, with 23 out of a total of 115 . The second most coded references (18) are "collaboration" and 'no tendering,' which are followed by 'trust and respect between stakeholders,' which has 15 coded references. Then there are 13 and 12 references for 'Jointly developed project goals' and 'Shared risk and rewards,' respectively. Lastly, there are other minor themes on "Decision making and control" and 'multi-party contracts,' each having only eight coded references and was only mentioned by 6 out of 10 participants. These results confirm the association between the literature study (Allison et al., 2018) and qualitative analysis.

Many of the main benefits and constraints of IPD-based project delivery highlighted in this study were similar to previous AEC research (Gomez et al., 2018, Ma et al., 2018, McGilly, 2017, Wood, 2017, Sarkar, 2015, AIA, 2007) Efficiency, improved quality, transparency of work, fewer change orders, cost reductions, and time savings were all the major advantages identified through literature and qualitative analysis. As highlighted in Figure 4, the highest number of references for 'benefits of IPD' are classified to enhanced project delivery with 21 references, simpler project delivery and time savings with 16 references each, and cost savings having 15 references. Reduced errors and risks, as well as fewer change orders, are the next most recognised advantages, with 12 and 10 references, respectively. Other identified benefits include improved coordination among stakeholders (9 references), sustainable buildings (6 references), waste reduction (6 references), easy operation and maintenance (4 references), incentives for successful project delivery (3 references) and transparency of work ( 2 references). In IPD, the project team collaborates using interactive technologies, ensuring that the project is completed in accordance with the client's specifications, saving time and money (Ahmed and El-Sayegh, 2021). As acknowledged by participant $\mathrm{H}$, these economic benefits are possible because cost estimates are established early in the design phase, and the contractor's constructability expertise can guide the design by minimising inefficiencies. Figure 4 reveals that, if effectively applied to infrastructure projects in India, the IPD method will bring numerous social, economic, and environmental advantages to the AEC sector. 
The mindset of individuals, lack of experience and skills, lack of awareness among owners, lack of interest to upgrade, non-availability of suitable IPD contracts, high investment cost, cultural setbacks, and fragmented approach in the industry are identified as the obstacles to the adoption of IPD in India. Participant E criticizes the fragmented approach in the industry by saying that:

"It should go without saying that this approach will benefit the industry, but owing to the industry's fragmented approach, everyone is trying to cover their backs and raise profits for themselves. They award the project to the lowest bidder, and then the contractor tries to circumvent the system by exploiting contract flaws."

IPD as a delivery approach has been discovered to be unknowing among the stakeholders. There is also considerable worry regarding the sort of contracts (usually multi-party contracts) that are used, which differ significantly from the contracts used in traditional delivery systems as the organizations and people are familiar and comfortable with them. It has been speculated that some professionals are hesitant to adopt IPD since the early participation of other stakeholders might have a negative influence on the design. The second major problem was a loss of control over the aesthetic aspects of design owing to the early involvement of contractors and subcontractors.

The analysis by word similarity performed during the qualitative analysis of data revealed some solutions that could resolve the challenges faced by the industry for the implementation of the IPD approach. These solutions include knowledge transfer via practice and theory to overcome the issue of skilled and experienced staff shortages. It also discusses how indisputable multi-party contracts may be used to avoid legal disputes between the project stakeholders. Another cluster outlines measures such as employee training, framework and standard development, and mindset reform, all of which may be achieved through government and client initiatives. Upon suggesting the solutions to overcome the setbacks, participant A said,

"We must bring some regulations into the way the entire professionals work together to deliver this more efficiently. Even the contracts written for architects, engineers or other consultants who get engaged in the project should be reviewed to ensure that responsibility is properly stated."

Both literature study and qualitative interview analysis revealed that the potential and benefits of implementing IPD in conjunction with BIM and advanced ICT are favourable. Furthermore, even if IPD may be accomplished without the use of Building Information Modelling (BIM), adoption of BIM is necessary to reach the level of collaboration required for optimal IPD (Elghaish and Abrishami, 2020, Wang et al., 2020, Elghaish et al., 2019a, Ma et al., 2018, Shendkar and Patil, 2017, Porwal and Hewage, 2013, AIA, 2007). BIM is a tool, not a project delivery method (Participant E); nevertheless, IPD approach methods operate in tandem with BIM and use the tool's capabilities (AIA, 2007). In response to the integration of ICTs and BIM with IPD, participant E said,

"These technologies you mentioned, such as blockchain, IoT and mixed realities, will be very useful if integrated with BIM process to deliver the project with IPD approach. Although IPD itself is just a delivery approach which can be applied individually, however its integration with BIM and all these ICT's helps to achieve its principles in an efficient and effective manner."

Furthermore, the cluster analysis combines the benefits that "Integrated Project Delivery" would bring to India if it were to be implemented effectively. By sharing risks and rewards and providing incentives for successful implementation, sustainable buildings may be achieved with waste reduction, capital savings, and reduced time for construction. It highlights that integrating IPD and BIM with modern ICT-based tools would increase stakeholders' collaboration and coordination, resulting in benefits such as improved and simplified project delivery, fewer change orders, and, eventually, reduced errors and threats. As a result, ICT tools like BIM and cloud applications are strongly recommended for usage with the IPD approach for optimising IPD delivery and developing the essential collaboration and trust among the IPD core team members. 


\section{CONCLUSION AND FUTURE WORKS}

In recent years, IPD research has received much interest. In the construction sector, several academics have shown the necessity of integrating ICT technologies and their characteristics, such as a shared data environment for cloud collaboration, blockchain for cost management, IOT for sustainable and efficient design, and mixed realities for enhanced coordination and collaboration. The benefits of IPD, as well as the role of ICT in delivering such benefits, have been widely researched and documented in the literature. Finding the advantages and disadvantages of this strategy, as well as the reasons for resistance and feasible solutions for its effective implementation, is important for a developing country's construction sector to expand sustainably. Organizations in such countries are still using inefficient, ineffective, and time-consuming techniques to coordinate and communicate with project stakeholders. The adoption of IPD in the construction sector in developing countries such as India is still in its infancy due to the contextual setbacks that many users encounter. However, it is argued that the adoption of new technology initiatives take time.

The present study examined the contextual setbacks that IPD and BIM adoption faces in India. According to the analysis, a lack of experience, expertise and excellence is one of the major obstacles to IPD adoption in India. Moreover, a few of the other identified setbacks are individual mindsets, a lack of awareness among owners, a lack of interest to upgrade, the absence of appropriate IPD contracts, high investment costs, cultural hurdles, and a fragmented approach in the sector. This paper has found out that integrated project delivery solutions can provide real-world answers to difficult project challenges. By facilitating easier cooperation between design disciplines and construction services, IPD delivers profits for companies by helping to eliminate waste and boost efficiency in all phases of design, procurement, and construction. IPD characteristics are adaptable and may be used in several contractual situations. IPD-aware team members can emphasize the traditional trio of the client, designer, and builder, or they can expand to include other design and construction associates. The project parties engage in an agreement through a multi-party contract which outlines each firm's responsibilities, liabilities, and rights, and compensation is determined by the project's overall success. IPD holds both the design and construction teams accountable for the project's overall performance, not just their part of it. This encourages each team member to not only complete their jobs to the best of their ability but also to share their expertise throughout the building process.

Professional leaders in the AEC industry increasingly realise the potential of integrating emerging digital technologies such as Cloud computing, BIM, Blockchain and Mixed Realities with tried-and-true workflow procedures resulting in significant productivity gains and reductions in RFIs, field disputes, waste, and project timelines. Clients are also getting more intelligent, and they are increasingly mandating the adoption of these techniques by adding them to the contracts in order to achieve greater results. Since each project brings unique and seldom replicated conditions, the AEC sector faces the distinctive problem of frequent design and process improvement of the technology and the organisation. The data management and streamlining framework to assist by BIM technologies are extremely valuable for managing the constant stream of variations that occurs in the construction project.

Policymakers and academics may utilise the themes raised in this study to build strategies for increasing IPD implementation in India. Once the regulatory framework is suitably altered to embrace IPD, and a few success cases are shown, the researcher is hopeful that the industry will overcome the cultural, technological, and financial barriers to the effective use of IPD for construction projects. In order to implement IPD in developing countries, the governments (being the most prevalent client for infrastructure projects) must make a strong policy push. Furthermore, as a case study, government should lead the way in using IPD for the implementation of its own projects. Even though new contracts exist that allow IPD, they have not been sufficiently examined and are not yet fully verified or recognised in the context of public procurement. Therefore, for effective adoption, regulatory agencies should develop standards and frameworks, create IPD-friendly contracts, and upskill the workforce through training and knowledge transfer.

The first area of future research could potentially focus on developing a decision-making policy in context to the Indian construction sector. Some strong case studies in India can be explored to support the present study and to gain insight into its application for future projects. Another area of research could include performing empirical studies in the AEC sectors of developing countries to compare the qualitative and quantitative data for the applicability of IPD with BIM and ICTs such as blockchain, Internet of Things (IoT), Mixed Realities and Cloud Collaboration. 


\section{REFERENCES}

ABOWITZ, D. A. \& TOOLE, T. M. 2010. Mixed method research: Fundamental issues of design, validity, and reliability in construction research. Journal of construction engineering and management, 136, 108-116.

ABRISHAMI, S., GOULDING, J. AND RAHIMIAN, F., 2020. Generative BIM workspace for AEC conceptual design automation: prototype development. Engineering, Construction and Architectural Management, 28(2), pp.482-509.

ABRISHAMI, S., GOULDING, J., POUR RAHIMIAN, F. AND GANAH, A., 2015. Virtual generative BIM workspace for maximising AEC conceptual design innovation. Construction Innovation, 15(1), pp.24-41.

ADETOLA, A., GOULDING, J. \& LIYANAGE, C. 2011. Collaborative engagement approaches for delivering sustainable infrastructure projects in the aec sector: A review. International journal of construction supply chain management, 01, 01-24.

AHMAD, I., AZHAR, N. \& CHOWDHURY, A. 2019. Enhancement of IPD Characteristics as Impelled by Information and Communication Technology. Journal of Management in Engineering, 35.

AHMED, S. \& EL-SAYEGH, S. 2021. Critical Review of the Evolution of Project Delivery Methods in the Construction Industry. Buildings, 11.

AHMED, S. AND SOBUZ, M., 2019. Challenges of implementing lean construction in the construction industry in Bangladesh. Smart and Sustainable Built Environment, 9(2), pp.174-207.

AIA 2007. Integrated Project Delivery: A guide. California: American Institute of Architects.

ALASHHAB, Z. R., ANBAR, M., SINGH, M. M., LEAU, Y.-B., AL-SAI, Z. A. \& ALHAYJA'A, S. A. 2021. Impact of coronavirus pandemic crisis on technologies and cloud computing applications. Journal of Electronic Science and Technology, 19, 100059.

Alleman, D., ANTOINE, A. L. C., STANFORD, M. S. \& MOLENAAR, K. R. 2020. Project Delivery Methods' Change-Order Types and Magnitudes Experienced in Highway Construction. Journal of Legal Affairs and Dispute Resolution in Engineering and Construction, 12.

ALLISON, M., ASHCRAFT, H., CHENG, R., KLAWENS, S. \& PEASE, J. 2018. Integrated project delivery: an action guide for leaders.

ANDARY, E. G., ABI SHDID, C., CHOWDHURY, A. \& AHMAD, I. 2020. Integrated project delivery implementation framework for water and wastewater treatment plant projects. Engineering, Construction and Architectural Management, 27, 609-633.

AZHAR, N., KANG, Y. \& AHMAD, I. U. 2014. Factors Influencing Integrated Project Delivery in Publicly Owned Construction Projects: An Information Modelling Perspective. Procedia Engineering, 77, $213-221$.

BABATUNDE, S., EKUNDAYO, D., UDEAJA, C. AND ABUBAKAR, U., 2020. An investigation into the sustainability practices in PPP infrastructure projects: a case of Nigeria. Smart and Sustainable Built Environment, ahead-of-print(ahead-of-print).

BALLARD, G. \& HOWELL, G. 2003. Lean project management. Building Research \& Information, 31, $119-133$.

BECERIK-GERBER, B. \& KENT, D. Implementation of Integrated Project Delivery and Building Information Modeling on a Small Commercial Project. 2010 Boston. Proceedings of CIB W89 Conference, Wentworth Institute of Technology.

BOLPAGNI, M. 2013. The Implementation of BIM within the Public Procurement. https://www.vttresearch.com/sites/default/files/pdf/technology/2013/T130.pdf. (Accessed date: 21/10/2021). 
CHANG, C.-Y., PAN, W. \& HOWARD, R. 2017. Impact of building information modeling implementation on the acceptance of integrated delivery systems: Structural equation modeling analysis. Journal of Construction Engineering and Management, 143, 04017044.

CHARLESRAJ, V. P. C. \& GUPTA, V. Analysis of the Perceptions of Beneficiaries and Intermediaries on Implementing IPD in Indian Construction. 36th International Symposium on Automation and Robotics in Construction (ISARC 2019), 2019 Delhi, India.

CHUNG, W. W. S., TARIQ, S., MOHANDES, S. R. \& ZAYED, T. 2020. IoT-based application for construction site safety monitoring. International Journal of Construction Management, 1-17.

DOSSICK, C. S., AZARI, R., KIM, Y.-W. \& EL-ANWAR, O. 2013. IPD in practice: Sustaining collaboration in healthcare design and construction. AEI 2013: Building Solutions for Architectural Engineering.

ELGHAISH, F. \& ABRISHAMI, S. 2020a. Developing a framework to revolutionise the 4D BIM process: IPDbased solution. Construction Innovation, 20, 401-420.

ELGHAISH, F. \& ABRISHAMI, S. 2020c. A centralised cost management system: exploiting EVM and ABC within IPD. Engineering, Construction and Architectural Management.

ELGHAISH, F., ABRISHAMI, S. \& HOSSEINI, M. R. 2020b. Integrated project delivery with blockchain: An automated financial system. Automation in construction, 114, 103182.

ELGHAISH, F., ABRISHAMI, S., ABU SAMRA, S., GATERELL, M., HOSSEINI, M. R. \& WISE, R. 2019 a. Cash flow system development framework within integrated project delivery (IPD) using BIM tools. International Journal of Construction Management, 21, 555-570.

ELGHAISH, F., ABRISHAMI, S., HOSSEINI, M. R., ABU-SAMRA, S. \& GATERELL, M. 2019b. Integrated project delivery with BIM: An automated EVM-based approach. Automation in Construction, 106, 102907.

EVANS, M., FARRELL, P., ELBELTAGI, E. \& DiON, H. 2021. Competency framework to integrate lean construction and integrated project delivery on construction megaprojects: towards a future of work global initiatives in multinational engineering organisations. Benchmarking: An International Journal, ahead-ofprint.

EXCELIZE. 2020. Integrated project management for India's infrastructure projects. Available: https://excelize.com/blog/integrated-project-management-for-indias-infrastructure-projects. (Accessed date: $21 / 10 / 2021)$.

GOMEZ, S., BALLARD, G., NADERPAJOUH, N. \& RUIZ, S. Integrated project delivery for infrastructure projects in Peru. 2018 Chennai. International Group for Lean Construction.

GOULDING, J. S. \& RAHIMIAN, F. P. 2012. Industry preparedness: advanced learning paradigms for exploitation. Construction innovation and process improvement, 409-433.

HALE, D. R., SHRESTHA, P. P., GIBSON JR., G. E. \& MIGLIACCIO, G. C. 2009. Empirical Comparison of Design/Build and Design/Bid/Build Project Delivery Methods. Journal of Construction Engineering and Management, 135.

HUNHEVICZ, J. J., BRASEY, P.-A., BONANOMI, M. M. M. \& HALL, D. 2020. Blockchain and Smart Contracts for Integrated Project Delivery: Inspiration from the Commons. EPOC 2020 Working Paper Proceedings.

IBEF. 2021. Infrastructure Sector in India. Available: https://www.ibef.org/industry/infrastructure-sectorindia.aspx [Accessed 06 30].

JEFFREY, L. B., EDWARD, C. W. \& MICHAEL, C. L. 2001. Design-Build: Planning Through Development, New York, McGraw-Hill Education.

KAMUNDA, A., RENUKAPPA, S., SURESH, S. \& JALLOW, H. 2021. BIM in the water industry: addressing challenges to improve the project delivery process. Engineering, Construction and Architectural Management, 28, 510-529. 
KIM, S. H., RYU, H. G. \& KANG, C. S. Development of an IoT-based construction site safety management system. 2018 2018. Springer, 617-624.

KIM, Y.-W. R., KHALED; LEE, HYUN WOO; ANGELEY, JEFF. Integrated Project Delivery in Public Projects: Limitations and Opportunities. Proceedings 24th Annual Conference of the International Group for Lean Construction, 2016. Boston.

KURWI, S. D., PETER; HASSAN, TAREK M. Integrating BIM and GIS in railway projects: A critical review. Proceedings of the 33rd Annual ARCOM Conference, 2017. Cambridge, UK.

LOULAKIS, M. C. H., R. Project delivery and procurement: Understanding the differences. Proc. DBIA/AIA Professional Design-Build Conference, 2000 Washington, DC, USA.

MA, Z., ZHANG, D. \& LI, J. 2018. A dedicated collaboration platform for Integrated Project Delivery. Automation in Construction, 86, 199-209.

MATHEWS, M., ROBLES, D. \& BOWE, B. 2017. BIM+Blockchain: A Solution to the Trust Problem in Collaboration? CITA BIM Gathering 2017. Technological University Dublin.

MCGILLY, P. 2017. Cloud Collaboration and Successful Integrated Project Delivery. Las Vegas.

MESA, H. A., MOLENAAR, K. R. \& ALARCÓN, L. F. 2016. Exploring performance of the integrated project delivery process on complex building projects. International Journal of Project Management, 34, 10891101.

MOF 2021. Economic Survey 2020-21. New Delhi: Government of India, Depatment of Economic Affairs. https://www.indiabudget.gov.in/economicsurvey/. (Accessed date: 21/10/2021).

MOSSMAN, A., BALLARD, G. \& PASQUIRE, C. 2010. Lean Project Delivery-innovation in integrated design \& delivery. Architectural Engineering and Design Management, 1-28.

OKERE, G. 2018. Comparison of DB to DBB on highway projects in Washington State, USA. International Journal of Construction Supply Chain Management, 8, 73-86.

OTHMAN, A. A. E. \& YOUSSEF, L. Y. W. 2021. A framework for implementing integrated project delivery in architecture design firms in Egypt. Journal of Engineering, Design and Technology, 19, 721-757.

OYETUNJI, A. A. \& ANDERSON, S. D. 2006. Relative Effectiveness of Project Delivery and Contract Strategies. Journal of Construction Engineering and Management, 132.

PAL, A. \& NASSARUDIN, A. 2020. Integrated Project Delivery adoption framework for construction projects in India. Berkeley: Annual Conference of the International Group for Lean Construction.

PARCHAMI JALAL, M., YAVARI ROUSHAN, T., NOORZAI, E. AND ALIZADEH, M., 2020. A BIM-based construction claim management model for early identification and visualization of claims. Smart and Sustainable Built Environment, 10(2), pp.227-257.

PIROOZFAR, P., FARR, E. R. P., ZADEH, A. H. M., INACIO, S. T., KILGALlON, S. \& JIN, R. 2019. Facilitating Building Information Modelling (BIM) using Integrated Project Delivery (IPD): A UK perspective. Journal of Building Engineering, 26.

PORWAL, A. \& HEWAGE, K. N. 2013. Building Information Modeling (BIM) partnering framework for public construction projects. Automation in Construction, 31, 204-214.

QSR. 2018a. Matrix coding query [Online]. QSR International. Available: https://helpnv.qsrinternational.com/12/win/v12.1.105-d3ea61/Content/queries/matrix-coding-query.htm [Accessed 08 2021].

QSR. 2018b. Mind Maps [Online]. QSR International. Available: https://helpnv.qsrinternational.com/12/mac/v12.1.105-d3ea61/Content/vizualizations/mindmaps.htm?Highlight=mind\%20map [Accessed 08 2021]. 
RADHAKRISHNAN, S. 2020. Implementation of BIM in Integrated Project Delivery (IPD). Available: https://www.planbim.io/blog/2020/06/08/implementation-of-bim-in-integrated-project-delivery/ [Accessed 06 08].

RAHIMIAN, F. P., IBRAHIM, R. \& BAHARUDIN, M. N. Using IT/ICT as a new medium toward implementation of interactive architectural communication cultures. 2008 International Symposium on Information Technology, 2008. IEEE, 1-11.

RAZZAQUE, M. A., MILOJEVIC-JEVRIC, M., PALADE, A. \& CLARKE, S. 2015. Middleware for internet of things: a survey. IEEE Internet of things journal, 3, 70-95.

ROY, D., MALSANE, S. \& SAMANTA, P. K. 2018. Identification of Critical Challenges for Adoption of Integrated Project Delivery. Lean Construction Journal, 0-15.

SALIM, M. S. \& MAHJOOB, A. M. R. 2020. Integrated project delivery (IPD) method with BIM to improve the project performance: a case study in the Republic of Iraq. Asian Journal of Civil Engineering, 21, 947 957.

SARKAR, D. 2015. A framework for development of Lean Integrated Project Delivery Model for infrastructure road projects. International Journal of Civil and Structural Engineering, 5.

SHEIKHKHOSHKAR, M., POUR RAHIMIAN, F., KAVEH, M., HOSSEINI, M. AND EDWARDS, D., 2019. Automated planning of concrete joint layouts with 4D-BIM. Automation in Construction, 107, p.102943.

SHEIKHKHOSHKAR, M., RAHIMIAN, F. P., KAVEH, M. H., HOSSEINI, M. R. \& EDWARDS, D. J. 2019. Automated planning of concrete joint layouts with 4D-BIM. Automation in construction, 107, 102943.

SHENDKAR, P. D. \& PATIL, S. B. 2017. Implementation of Integrated Project Delivery (IPD) using Building Information Modelling (BIM). International Journal for Scientific Research \& Development, 5.

SHRESTHA, P. P., O’CONNOR, J. T. \& GIBSON, G. E. 2012. Performance Comparison of Large Design-Build and Design-Bid-Build Highway Projects. Journal of Construction Engineering and Management, 138, 113.

SINGHAPUTTANGKUL, N., 2017. A decision support tool to mitigate decision-making problems faced by a building design team. Smart and Sustainable Built Environment, 6(1), pp.2-18.

TAGLiaBUE, L. C. \& CIRIBINI, A. L. C. 2018. A BIM-Based IoT Approach to the Construction Site Management. IN_BO. Ricerche e progetti per il territorio, la città e l'architettura, 9, 136-145.

TAYLOR, S. J., BOGDAN, R. \& DEVAULT, M. 2015. Introduction to qualitative research methods: A guidebook and resource, John Wiley \& Sons.

TEIZER, J., WOLF, M., GOLOVINA, O., PERSCHEWSKI, M., PROPACH, M., NEGES, M. \& KÖNIG, M. Internet of Things (IoT) for integrating environmental and localization data in Building Information Modeling (BIM). 2017 2017. IAARC Publications.

WANG, Y., THANGASAMY, V. K., HOU, Z., TIONG, R. L. K. \& ZHANG, L. 2020. Collaborative relationship discovery in BIM project delivery: A social network analysis approach. Automation in Construction, 114, 103-147.

WHELTON, M., BALLARD, G. \& TOMMELEIN, I. Application of design rationale systems to project definition - Establishing a research project. 2001 Berkeley. Proceedings of the 2007 annual conference of the International Group for Lean Construction.

WOOD, R. R. 2017. Building Information Modeling (BIM) and Integrated Project Delivery (IPD) for "Large scale projects in Asian markets at par with global standards. Autodesk University 2017 [Online].

ZAINUL ABIDIN, N. AND AMIR SHARIFFUDDIN, N., 2019. Engaging consultants in green projects: exploring the practice in Malaysia. Smart and Sustainable Built Environment, 8(1), pp.80-94. 